\author{
Wojciech Cymerman* \\ Uniwersytet Przyrodniczy w Lublinie \\ Joanna Cymerman** \\ Politechnika Koszalińska
}

\title{
WYKORZYSTANIE WSPÓŁCZYNNIKA ZMIENNOŚCI DO OCENY NIERUCHOMOŚCI PODOBNYCH W PROCESIE SZACOWANIA NIERUCHOMOŚCI
}

\begin{abstract}
Streszczenie
Publikację poświęcono możliwości wykorzystania jednego z podstawowych parametrów opisowych zbiorowości statystycznych, jakim jest współczynnik zmienności, do oceny zestawu nieruchomości podobnych w procesie szacowania. Określono wartości tego współczynnika dla teoretycznego rozkładu równomiernego oraz normalnego w zależności od różnicy: jednostkowa cena maksymalna - jednostkowa cena minimalna. W części aplikacyjnej opracowania zaprezentowano wyniki analiz przeprowadzonych na etapie doboru nieruchomości podobnych (przy wykorzystaniu współczynnika zmienności) w procesie wykonywania dwóch operatów szacunkowych określających wartość nieruchomości lokalowych. Nieruchomości te są zlokalizowane w miejscowościach Polanów oraz Mielno, powiatu koszalińskiego, w województwie zachodniopomorskim. Dane do analiz pozyskano z Rejestru Cen i Wartości Nieruchomości (RCiWN).
\end{abstract}

Słowa kluczowe: wycena nieruchomości, nieruchomość podobna, współczynnik zmienności

* Adres e-mail: wojciech.cymerman@up.lublin.pl.

** Adres e-mail: joanna.cymerman@wilsig.tu.koszalin.pl. 


\section{Wprowadzenie}

W świetle zapisów ustawy o gospodarce nieruchomościami oraz rozporządzenia w sprawie wyceny nieruchomości i sporządzania operatu szacunkowego (Ustawa 2007, art. 4 pkt 6, 6a; Rozporządzenie 2004, § 3) wycena nieruchomości stanowi postępowanie zmierzające do określenia wartości nieruchomości jako przedmiotu prawa własności lub innych praw, które poprzedza się analizą rynku nieruchomości, w szczególności w zakresie uzyskiwanych cen, stawek czynszów oraz warunków zawarcia transakcji. W każdej analizie danych porównawczych, we wszystkich podejściach do wyceny, szczególnie istotne jest, by nieruchomości, których dane są zbierane, miały cechy rynkowe podobne do wycenianej nieruchomości, a więc by zachowane było kryterium ,podobieństwa nieruchomości” (Hopfer 2015). Według Stownika języka polskiego $P W N$ podobny (synonimy: izomorficzny, paralelny, bliski, zbliżony, analogiczny) to „mający pewne cechy wspólne z czymś, z kimś; taki jak inny, o którym była mowa poprzednio lub który się ma na myśli" (Słownik języka... 2015). W polskim systemie prawa kategoria „podobieństwa” występuje zarówno w obszarze prawa cywilnego, jak i administracyjnego. Na płaszczyźnie wyceny nieruchomości oficjalną definicję nieruchomości podobnej zawiera art. 4 pkt 16 ustawy o gospodarce nieruchomościami, zgodnie z którym nieruchomość podobna to „nieruchomość porównywalna z nieruchomością stanowiącą przedmiot wyceny ze względu na położenie, stan prawny, przeznaczenie, sposób korzystania z nieruchomości oraz inne cechy wpływające na wartość". Przywołana definicja przysparza rzeczoznawcom majątkowym sporo problemów z uwagi na małą precyzyjność (Zyga 2011, s. 142-143; Foryś 2010, s. 95-106). W literaturze powszechnie zwraca się również uwagę na obiektywne trudności występujące w analizie rynku nieruchomości, wynikające z jego cech specyficznych, głównie: niejednolitości, niedoskonałości i niskiej elastyczności (Kucharska-Stasiak 2006, s. 43-53; Bryx 2006, s. 43-58). Dodatkowo różnorodność nieruchomości (bark dwóch identycznych nieruchomości) oraz mała przejrzystość rynku (brak pełnej informacji po stronie uczestników rynku) skutkują tym, że cechy nieruchomości nie znajdują pełnego odwzorowania w ich cenach - nieefektywność rynku (Kucharska-Stasiak 2010, s. 7-15).

Mając powyższe na uwadze, kwestia poprawnego doboru nieruchomości podobnych przez rzeczoznawcę majątkowego nie jest zadaniem błahym i niesie za sobą skutki dotyczące poprawności wykonania kolejnych etapów wyceny nierucho- 
mości. Wszystkie informacje związane z rynkiem nieruchomości mają charakter probabilistyczny (wpływ czynników losowych), co obliguje rzeczoznawców majątkowych do stosowania w procesie szacowania nieruchomości narzędzi statystyki matematycznej (Czaja, Ligas 2011, s. 7-20).

Poszukując instrumentów zapewniających podobieństwo nieruchomości, należałoby, w myśl zasad prawdopodobieństwa, analizować rozkłady empiryczne cen jednostkowych przez testy nieparametryczne. By takie badania przeprowadzić, potrzebna jest jednak odpowiednia liczebność próby, a także znajomość teorii w tym zakresie. W powszechnej praktyce próby nieruchomości podobnych, przyjmowane przez rzeczoznawców do wygenerowania wartości, mają małą liczebność. Te czynniki sprawiają, że należy poszukiwać innych sposobów oceny podobieństwa. W takim kontekście autorzy postanowili sprawdzić możliwość wykorzystania w tym celu miernika statystycznego, jakim jest współczynnik zmienności. Przeprowadzono wywód związany z wielkością takiego współczynnika w zależności od rozpiętości cenowej $1 \mathrm{~m}^{2}$ (amplitudy cenowej $1 \mathrm{~m}^{2}$ ) przy rozkładzie normalnym i rozkładzie równomiernym.

W dalszej części opracowania zaprezentowano wykorzystanie tego współczynnika do oceny nieruchomości podobnych na przykładzie praktycznym.

\section{Elementy statystyki matematycznej w wycenie nieruchomości}

W wycenie nieruchomości, w procesie doboru nieruchomości podobnych można wykorzystać niektóre elementarne narzędzia statystyki matematycznej. Z całej gamy różnych mierników statystycznych najczęściej stosowane w procesie wyceny nieruchomości są: średnie klasyczne (arytmetyczna, geometryczna, harmoniczna), średnie nieklasyczne (średnia mediana, średnia modalna), odchylenie standardowe oraz współczynniki (zmienności, asymetrii, skupienia, korelacji). Niektóre z wyżej wymienionych mierników stosowane są naturalnie bez powiązania tego faktu $\mathrm{z}$ teorią statystyki. Często podczas analizy rynku w zakresie przyjętych jednostek porównawczych zwraca się szczególną uwagę na powtarzające się bądź bardzo bliskie sobie wartości, szukając tym samym najbardziej prawdopodobnych wartości reprezentujących rynek lokalny. Takie postępowanie jest jak najbardziej zbieżne $\mathrm{z}$ poszukiwaniem wartości modalnej z danego zbioru. 
W praktyce najczęściej stosowanym miernikiem w procesie wyceny jest średnia arytmetyczna, z kolei dwie pozostałe średnie klasyczne: harmoniczna i średnia geometryczna, stosowane są bardzo rzadko. Należy w tym miejscu wspomnieć, że często, mając niejednakowe zaufanie do wyników pozyskanych w obliczeniach, wprowadza się wagi, by zrównoważyć wpływ wyników na obliczany rezultat. W procesie wyceny definicja wagi jest nieco inna niż w podręcznikach matematycznych, tym niemniej proces obliczania średniej arytmetycznej ważonej jest taki sam.

Nieobce rzeczoznawcom majątkowym są działania przypominające wyznaczanie mediany. Mając wystarczającą liczebność próby, układa się przyjęte jednostki porównawcze w porządku rosnącym bądź malejącym, by wyznaczyć wartość środkową z takiej próby, czyli jej medianę. Taki sam sposób jest także realizowany przy wyznaczaniu kwartyli. Mając wystarczającą liczebność próby, rzeczoznawca do konkretnych analiz może przyjąć dwa kwartyle, eliminując tym samym skrajne wartości z próby, które mogą mieć charakter wymuszonych transakcji (wyniki odstające).

\section{Współczynnik zmienności - rozkład równomierny, rozkład normalny}

Współczynnik zmienności jest wielkością niemianowaną. Może być wyrażany za pomocą procentów, co ma duże znaczenie w praktyce, pozawala bowiem wykorzystywać ten miernik do porównywania prób zawierających elementy różnoimienne (zob. Lange, Banasiński 1970, s. 58; Krysicki et al. 1998, s. 28; Brandt 1976, s. 114). Odwzorowuje on relacje skupienia elementów próby do wartości średniej, co w szacowaniu nieruchomości jest bardzo istotne. Fakt ten pozawala na ocenę jakości próby pod względem jej wartości średniej oraz rozproszenia.

Mając bazę cen transakcyjnych nieruchomości podobnych zaktualizowaną na datę wyceny, przyjmuje się najczęściej, że mają one rozkład równomierny (prostokątny, jednostajny) lub rozkład normalny. Przyjęcie rozkładu równomiernego jest równoznaczne z założeniem, że każda cena jednostkowa w tej próbie ma takie samo prawdopodobieństwo pojawienia się. Przyjęcie założenia o rozkładzie normalnym oznacza, że wartości znajdujące się bliżej estymatora wartości oczekiwanej, jakim jest średnia arytmetyczna, mają większe prawdopodobieństwo zaistnienia niż wartości znacznie odbiegające od tego estymatora. Przeanalizujmy teraz współczynnik 
zmienności w rozkładzie równomiernym w zależności od rozpiętości ceny maksymalnej i ceny minimalnej: $\Delta C=c_{\max }-c_{\min }$.

Jak wiadomo, rozkład równomierny opisany jest funkcją gęstości prawdopodobieństwa:

$$
f(x)=\left\{\begin{array}{cc}
\frac{1}{b-a} & \text { dla } x \in\langle a ; b\rangle \\
0 & \text { dla pozostałych } x
\end{array}, \text { gdzie } b>a\right.
$$

Wartość oczekiwana (w praktyce estymatorem tego parametru jest średnia arytmetyczna) w takim rozkładzie określana jest wzorem:

$$
E(X)=\frac{a+b}{2}
$$

natomiast odchylenie standardowe w tym rozkładzie wynosi:

$$
\sigma=\sqrt{\frac{(b-a)^{2}}{12}}=\frac{\sqrt{3}(b-a)}{6}
$$

Jak można zauważyć, wpływ na wartość tego parametru mają wartości skrajne, niezależnie od elementów występujących w próbie.

Zakładając, że zaktualizowane ceny jednostkowe) $\left(\mathrm{m}^{2}\right)$ przyjmują wartości $\mathrm{z}$ przedziału $\left\langle c_{\min } ; c_{\max }\right\rangle$, rozstęp cenowy danej próby wynosi:

$$
\Delta C=c_{\max }-c_{\min }
$$

Przyjmując, że

$$
c_{\max }=k \cdot c_{\min }
$$

i przy założeniu, że $c_{\text {min }}>0$, gdzie $k$ jest współczynnikiem (parametrem) wielokrotności ceny minimalnej $c_{m i n}$, współczynnik zmienności można zapisać wzorem:

$$
\Delta C=k \cdot c_{\min }-c_{\min }=c_{\min } \cdot(k-1)
$$


Widać, że gdy $c_{\max }$ jest dwukrotnie wyższa od $c_{\min }$, wówczas $\Delta C=c_{\min }$ i $k=2$, natomiast gdy $k=3$, to $\Delta C=2 \cdot c_{\text {min }}$ itd. Zatem współczynnik ten wyraża relację między ceną minimalną $c_{\min }$ a $\Delta C$ (rozpiętością cenową w próbie).

Uwzględniając wcześniej przyjęte założenie, że zaktualizowane ceny jednostkowe mają rozkład równomierny, funkcję gęstości prawdopodobieństwa można zapisać wzorem:

$$
f(x)=\left\{\begin{array}{cl}
\frac{1}{c_{\max }-c_{\min }} & \text { dla } x \in\left\langle c_{\min } ; c_{\max }\right\rangle \\
0 & \text { dla pozostałych } x
\end{array}\right.
$$

W tej sytuacji parametry opisowe, takie jak wartość oczekiwana i odchylenie standardowe zmiennej losowej, przyjmą postać:

$$
E(X)=\frac{c_{\min }+c_{\max }}{2}, \sigma=\frac{\sqrt{3}\left(c_{\max }-c_{\min }\right)}{6}
$$

Przyjmując założenia opisane formułą (5), powyższe parametry można zapisać:

$$
E(X)=\frac{c_{\min } \cdot(1+k)}{2}, \sigma=\frac{\sqrt{3} \cdot c_{\min } \cdot(k-1)}{6}
$$

Wobec tego współczynnik zmienności wynosi:

$$
\omega=\frac{\sigma}{E(X)}=\frac{\frac{\sqrt{3} \cdot c_{\min } \cdot(k-1)}{6}}{\frac{c_{\min } \cdot(1+k)}{2}}=\frac{\sqrt{3} \cdot(k-1)}{3 \cdot(k+1)}
$$

Współczynnik zmienności zależny jest tylko od parametru $k$, odwzorowującego relacje między ceną minimalną $c_{\text {min }}$, a ceną maksymalną $c_{\max }$. 
W praktyce często występuje założenie, że większość zjawisk ma rozkład normalny. Można zatem takie założenie przyjąć w odniesieniu do zaktualizowanych cen jednostkowych $\left(\mathrm{m}^{2}\right) \mathrm{z}$ przedziału $\left(c_{\text {min }} ; c_{\text {max }}\right)$. Jeśli ponadto przyjmie się, że zaktualizowane ceny analizowanej próby mają rozkład normalny bez asymetrii, to funkcja gęstości prawdopodobieństwa tego rozkładu ma postać:

$$
f(x)=\frac{1}{\sigma \sqrt{2 \pi}} \exp \left[\frac{(x-E(X))^{2}}{2 \sigma^{2}}\right]
$$

Z teorii rozkładu normalnego wynika, że prawdopodobieństwo, iż prawdziwa wartość zmiennej losowej znajdzie się w przedziale $\langle E(X)-3 \sigma ; E(X)+3 \sigma\rangle$, wynosi 0,9973. Można zatem bez większego ryzyka założyć, że wszystkie wyniki znajdują się w tym przedziale. Zatem

$$
\Delta C=6 \sigma
$$

Przyjmując, tak jak w rozkładzie równomiernym, że $c_{\max }=k \cdot c_{\min }$, mamy:

$$
E(X)=\frac{c_{\min }+c_{\max }}{2}=\frac{c_{\min }}{2} \cdot(1+k)
$$

oraz

$$
\Delta C=c_{\max }-c_{\min }=c_{\min } \cdot(k-1)
$$

Mając na uwadze (12), można zatem zapisać

$$
6 \sigma=c_{\min } \cdot(k-1)
$$

czyli

$$
\sigma=\frac{c_{\min } \cdot(k-1)}{6}
$$


Wobec tego współczynnik zmienności w przypadku rozkładu normalnego ma postać:

$$
\omega=\frac{\sigma}{E(X)}=\frac{\frac{c_{\min } \cdot(k-1)}{6}}{\frac{c_{\min } \cdot(k+1)}{2}}=\frac{k-1}{3(k+1)}
$$

Podobnie jak w rozkładzie równomiernym, wartość tego miernika jest funkcją jednego argumentu, jakim jest wielkość $k$ - współczynnik (parametr) pokazujący relację między ceną minimalną a ceną maksymalną. Współczynnik ten odzwierciedla także relacje $\Delta C$ do ceny minimalnej oraz maksymalnej.

W poniższej tabeli przedstawiono kilka wyników obliczeń współczynnika zmienności dla początkowych wartości $k$, nawiązując tym samym do relacji wartości $\Delta C \mathrm{w}$ odniesieniu do ceny minimalnej i analizując rozkład równomierny oraz rozkład normalny (tabela 1 ).

Tabela 1. Wartość współczynnika zmienności dla początkowych wartości $k$ przy rozkładzie równomiernym i normalnym

\begin{tabular}{|c|c|c|c|}
\hline \multirow{2}{*}{$k$} & \multirow{2}{*}{$\Delta C$} & Rozkład równomierny & Rozkład normalny \\
\cline { 3 - 4 } & & $\omega=\frac{\sqrt{3}(k-1)}{3(k+1)}$ & $\omega=\frac{(k-1)}{3(k+1)}$ \\
\cline { 3 - 4 } & & 0,192 & 0,111 \\
\hline 2 & $\Delta C=c_{\min }$ & 0,289 & 0,167 \\
\hline 3 & $\Delta C=2 \cdot c_{\min }$ & 0,346 & 0,200 \\
\hline 4 & $\Delta C=3 \cdot c_{\min }$ & 0,385 & 0,222 \\
\hline 5 & $\Delta C=4 \cdot c_{\min }$ & & \\
\hline
\end{tabular}

Źródło: Cymerman, Cymerman (2014).

Z analizy powyższych rozwiązań wynika, że rozkład normalny jest bardziej wymagający w zakresie współczynnika zmienności. Przy $\Delta C=c_{\min }$ współczynnik 
zmienności dla rozkładu normalnego wynosi 0,111 , w rozkładzie równomiernym zaś jest większy i ma wartość 0,192 . Jak można zauważyć na podstawie wzorów określających ten miernik w rozkładzie równomiernym, jego wartość jest w każdym przypadku $\sqrt{3}$ razy większa niż w rozkładzie normalnym.

W praktyce najczęściej przyjmowany jest postulat, by $\Delta C<c_{\text {min }}$. W takim przypadku współczynnik zmienności nie powinien przekraczać 19\% dla rozkładu równomiernego lub $11 \%$ dla rozkładu normalnego. Zdarzają się jednak sytuacje, zwłaszcza dla nieruchomości o niskich cenach jednostkowych, np. rolnych, że rzeczoznawca nie jest w stanie na podstawie dostępnej bazy wygenerować próby spełniającej postulat, by $\Delta C<c_{\min }$. Według autorów w takich sytuacjach należy przyjąć zasadę, by mimo większych relacji $\Delta C$ do $c_{\text {min }}$ współczynnik zmienności był odpowiednio mniejszy od wartości obliczonych na podstawie zaproponowanych wzorów. Spełnienie tych warunków będzie jednym z kilku elementów świadczących o podobieństwie nieruchomości w analizowanej próbie.

\section{Praktyczne zastosowanie współczynnika zmienności w wycenie nieruchomości w procesie doboru nieruchomości podobnych}

W niniejszym rozdziale zaprezentowano wyniki analiz przeprowadzonych na etapie doboru nieruchomości podobnych przy wykorzystaniu współczynnika zmienności w procesie szacowania wartości dwóch nieruchomości lokalowych położonych w miejscowościach Polanów i Mielno powiatu koszalińskiego w województwie zachodniopomorskim.

W procesie wyceny nieruchomości lokalowej w Polanowie przeanalizowano transakcje z okresu 16 miesięcy (1.01.2013-30.04.2014), wyłaniając 13 nieruchomości podobnych do wycenianej (tabela 2 ) i identyfikując 4 cechy rynkowe wpływające na zróżnicowanie cen: lokalizację, powierzchnię użytkową lokalu, stan techniczny budynku, występowanie pomieszczeń przynależnych (więcej o doborze zmiennych w: Batóg, Foryś 2013, s. 36-50). 
Tabela 2. Zbiór cen transakcyjnych nieruchomości podobnych z lokalnego rynku w Polanowie

\begin{tabular}{|c|c|c|c|c|}
\hline Lp. & Data transakcji & $\begin{array}{c}\text { Powierzchnia } \\
\text { użytkowa lokalu } \\
{\left[\mathrm{m}^{2}\right]}\end{array}$ & $\begin{array}{c}\text { Cena } \\
\text { transakcyjna [zł] }\end{array}$ & $\begin{array}{c}\text { Cena 1 m² powierzchni } \\
\text { użytkowej lokalu zaktualizo- } \\
\text { wana na datę wyceny [zł] }\end{array}$ \\
\hline 1 & $2014-04-28$ & 36,59 & 65000 & 1773,06 \\
\hline 2 & $2014-04-25$ & 48,35 & 77000 & 1589,52 \\
\hline 3 & $2014-02-04$ & 40,36 & 55000 & 1359,63 \\
\hline 4 & $2013-12-13$ & 70,78 & 102000 & 1437,25 \\
\hline 5 & $2013-12-12$ & 46,96 & 66000 & 1401,71 \\
\hline 6 & $2013-12-12$ & 34,15 & 48000 & 1401,82 \\
\hline 7 & $2013-12-03$ & 45,24 & 60000 & 1322,73 \\
\hline 8 & $2013-10-31$ & 45,43 & 80000 & 1943,60 \\
\hline 9 & $2013-09-26$ & 50,00 & 97500 & 2014,47 \\
\hline 10 & $2013-07-24$ & 64,30 & 130000 & 2182,80 \\
\hline 11 & $2013-06-21$ & 59,33 & 130000 & 2525,09 \\
\hline 12 & $2013-05-24$ & 17,75 & 45000 & 2309,17 \\
\hline 13 & $2013-01-24$ & 47,41 & 110000 & \\
\hline
\end{tabular}

Źródło: opracowanie własne na podstawie RCWN.

$$
\begin{array}{rc}
c_{\text {max }}=2525,09 \frac{\mathrm{zl}}{\mathrm{m}^{2}} & k=1,91 \\
c_{\text {min }}=1322,73 \frac{\mathrm{zl}}{\mathrm{m}^{2}} & \Delta C=1202,36 \frac{\mathrm{zl}}{\mathrm{m}^{2}} \\
c_{s r}=1770,50 \frac{\mathrm{zl}}{\mathrm{m}^{2}} & \sigma=382,74 \frac{\mathrm{zl}}{\mathrm{m}^{2}}
\end{array}
$$

Dla analizowanej próby przy obliczonym współczynniku $k$ otrzymujemy

$$
\omega=0,216
$$

rozkład równomierny

$$
\omega=0,180
$$

rozkład normalny

$$
\omega=0,104
$$

Otrzymany wynik $\omega=0,216$ jest dwukrotnie większy niż teoretyczna wartość tego miernika dla rozkładu normalnego (przy otrzymanej wartości $k$ ) oraz niewiele 
większy od odpowiedniego parametru w rozkładzie równomiernym. Może to oznaczać, że wyniki tej próby mają rozkład bardziej zbliżony do równomiernego niż normalnego. By taką tezę jednak postawić, należałoby zweryfikować hipotezę nieparametryczną, co przy takiej liczebności próby jest niewskazane. Tym niemniej współczynnik $\omega=0,216$, mimo że przekracza teoretyczne wartości rozkładu równomiernego, nie dyskwalifikuje analizowanej próby. Może być natomiast porównywany z takim współczynnikiem dla innej próby. Taka wartość może być spowodowana dosyć rozległym okresem, z jakiego pochodzą transakcje.

W procesie wyceny nieruchomości położonej $\mathrm{w}$ Mielnie przeanalizowano transakcje z okresu 9 miesięcy (1.09.2013-31.05.2014), wyłaniając 21 nieruchomości podobnych do wycenianej (tabela 3 ) i identyfikując 2 cechy rynkowe wpływające na zróżnicowanie cen: lokalizację i powierzchnię użytkową lokalu.

Tabela 3. Zbiór cen transakcyjnych nieruchomości podobnych z lokalnego rynku w gminie Mielno

\begin{tabular}{|c|c|c|c|c|}
\hline Lp. & Data transakcji & $\begin{array}{c}\text { Powierzchnia } \\
\text { użytkowa lokalu } \\
{\left[\mathrm{m}^{2}\right]}\end{array}$ & $\begin{array}{c}\text { Cena } \\
\text { transakcyjna [zł] }\end{array}$ & $\begin{array}{c}\text { Cena 1 m² powierzchni użytko- } \\
\text { wej lokalu zaktualizowana } \\
\text { na datę wyceny [zł] }\end{array}$ \\
\hline 1 & 2 & 3 & 4 & 5 \\
\hline 1 & $2014-05-20$ & 76,26 & 775400 & 10191,62 \\
\hline 2 & $2014-04-11$ & 33,84 & 260000 & 7703,19 \\
\hline 3 & $2014-04-16$ & 33,75 & 250000 & 7426,67 \\
\hline 4 & $2014-04-08$ & 34,42 & 287000 & 8359,86 \\
\hline 5 & $2014-02-27$ & 35,14 & 260000 & 7422,06 \\
\hline 6 & $2014-02-18$ & 46,40 & 319000 & 6901,16 \\
\hline 7 & $2014-01-08$ & 28,33 & 183000 & 6463,75 \\
\hline 8 & $2013-12-31$ & 31,78 & 220000 & 6947,79 \\
\hline 9 & $2013-12-31$ & 31,83 & 220000 & 6936,88 \\
\hline 10 & $2013-12-13$ & 28,00 & 299000 & 10726,41 \\
\hline 11 & $2013-11-19$ & 30,46 & 186000 & 6130,18 \\
\hline 12 & $2013-11-26$ & 28,15 & 288549 & 10290,39 \\
\hline 13 & $2013-11-18$ & 52,76 & 539000 & 7629,64 \\
\hline 14 & $2013-11-19$ & 33,53 & 254828 & \\
\hline & & & & 10252,57 \\
\hline
\end{tabular}




\begin{tabular}{|c|c|c|c|c|}
\hline 1 & 2 & 3 & 4 & 5 \\
\hline 15 & $2013-11-25$ & 35,92 & 290000 & 8104,99 \\
\hline 16 & $2013-11-18$ & 35,80 & 249000 & 6982,44 \\
\hline 17 & $2013-10-31$ & 33,62 & 320000 & 9557,73 \\
\hline 18 & $2013-10-31$ & 27,75 & 202000 & 7309,56 \\
\hline 19 & $2013-10-24$ & 38,70 & 320000 & 8303,13 \\
\hline 20 & $2013-09-26$ & 30,70 & 195000 & 6374,06 \\
\hline 21 & $2013-09-12$ & 53,71 & 450000 & 8415,36 \\
\hline
\end{tabular}

Źródło: opracowanie własne na podstawie RCWN.

$$
\begin{array}{cc}
c_{\text {max }}=10726,41 \frac{\mathrm{zl}}{\mathrm{m}^{2}} & k=1,75 \\
c_{\text {min }}=6130,18 \frac{\mathrm{zl}}{\mathrm{m}^{2}} & \Delta C=4596,23 \frac{\mathrm{zl}}{\mathrm{m}^{2}} \\
c_{\text {sr }}=8020,25 \frac{\mathrm{zl}}{\mathrm{m}^{2}} & \sigma=1375,36 \frac{\mathrm{zl}}{\mathrm{m}^{2}}
\end{array}
$$

Dla analizowanej próby przy obliczonym współczynniku $k$ otrzymujemy

$$
\omega=0,171
$$

rozkład równomierny

$$
\omega=0,157
$$

rozkład normalny

$$
\omega=0,091
$$

Uzyskany w tym przypadku współczynnik zmienności $\omega=0,171$ jest bardzo bliski wartości, jakie dla tych danych sugeruje teoretyczny rozkład równomierny. Mimo większych co do wartości bezwzględnej różnic w danych ten zestaw transakcji jest lepszy pod względem podobieństwa w ocenie statystycznej. Poniekąd takiej oceny można było się spodziewać, uwzględniając fakt, że nieruchomości podobne w tym przypadku różniły się tylko dwiema cechami rynkowymi, podczas gdy w przypadku rynku miasta Polanów - czterema. 


\section{Podsumowanie}

Jak nadmieniono już na wstępie, ocena podobieństwa nieruchomości jest skomplikowana. Zapewne nie rozstrzygnie tej kwestii pojedynczy parametr, jakim jest współczynnik zmienności. Zdaniem autorów przeprowadzone rozważania mogą jednak posłużyć do wypracowania sposobów, które pozwalałyby oceniać, jaka próba przyjętych transakcji jest odpowiednia (wystarczająca) do przeprowadzenia poprawnego procesu wyceny. Na podstawie przeprowadzonych analiz można sugerować, by wartość graniczna współczynnika zmienności w próbie przyjętej do wyceny nieruchomości była mniejsza od $\omega=0,200$. Jest to wartość otrzymana przy rozkładzie normalnym dla $\Delta C=3 c_{\text {min }}$, która jest zbliżona do wyników otrzymanych w rozkładzie równomiernym $(\omega=0,192)$ dla $\Delta C=c_{\text {min }}$. Z analiz rozkładu normalnego otrzymujemy, że cena minimalna stanowi trzykrotną wartość odchylenia standardowego. Można z tego wnioskować, że cena minimalna nie powinna być mniejsza od trzykrotnej wartości błędu średniego, w myśl znanej reguły o tej nazwie.

W literaturze można znaleźć sugestie, że zbiory, gdzie $\omega>0,3$, pod względem podobieństwa oceniane są jako słabe (Czaja 1996, s. 3). Podobieństwo odwzorowuje się w ostatecznych analizach przez cenę, czym większe zatem rozbieżności cen, tym jest ono słabsze. Im mniejsza wartość tego miernika, tym jakość próby pod względem statystycznej zgodności będzie lepsza.

\section{Literatura}

Batóg B., Foryś I. (2013), Zastosowanie modeli zmiennych jakościowych do badania wplywu cech mieszkań na cenę rynkowa kwalifikujaca je do finansowania w programie „Rodzina na swoim”, „Wiadomości Statystyczne”, nr 5 (624), s. 36-50.

Brandt S. (1976), Metody statystyczne i obliczeniowe analizy danych, PWN, Warszawa.

Bryx M. (2006), Rynek nieruchomości. System i funkcjonowanie, Poltex, Warszawa.

Cymerman W., Cymerman M. (2014), Wykorzystanie elementów statystyki do analiz rynkowych $w$ procesie wyceny nieruchomości w podejściu porównawczym metoda porównywania parami i korygowania ceny średniej, „Wycena”, z. 4 (109).

Czaja J. (1996), Elementy rachunku prawdopodobieństwa i statystyki matematycznej w wycenie nieruchomości, Vademecum Rzeczoznawcy Nieruchomości. Zeszyt Problemowy nr 3, Szkoła Wiedzy o Terenie, Kraków. 
Czaja J., Ligas M. (2011), Zaawansowane metody analizy statystycznej rynku nieruchomości, „Studia i Materiały TNN”, vol. 19, nr 4.

Foryś I. (2010), Wykorzystanie metod taksonomicznych do wyboru obiektów podobnych w procesie szacowania lokali mieszkalnych, „Studia i Materiały TNN”, vol. 18, nr 1.

Hopfer A. (14.06.2015), Analiza rynku nieruchomości, http://wsgn-zkola.cba.pl/ryneknieruchomosci-01.pdf.

Krysicki W. et al. (1998), Rachunek prawdopodobieństwa i statystyka matematyczna w zadaniach, Wydawnictwo Naukowe PWN, Warszawa.

Kucharska-Stasiak E. (2006), Nieruchomość w gospodarce rynkowej, Wydawnictwo Naukowe PWN, Warszawa.

Kucharska-Stasiak E. (2010), Odwzorowanie cech nieruchomości w cechach i skutki dla procesu wyceny, „Studia i Materiały TNN”, vol. 18, nr 3.

Lange O., Banasiński A. (1970), Teoria statystyki, PWE, Warszawa.

Rozporządzenie Rady Ministrów z dnia 21 września 2004 r. w sprawie wyceny nieruchomości i sporządzania operatu szacunkowego, DzU z 2004 r., nr 207, poz. 2109 ze zm.

Słownik języka polskiego PWN (15.06.2015), http://sjp.pwn.pl/szukaj/podobny.html.

Ustawa z dnia 21 sierpnia 1997 r. o gospodarce nieruchomościami, tj. DzU z 2015 r., poz. 1774 ze zm.

Zyga J. (2011), Identyfikacja podobieństwa nieruchomości, „Studia i Materiały TNN”, vol. $19, \mathrm{nr} 4$.

\title{
POSSIBLE USES OF THE COEFFICIENT OF VARIATION IN THE PROCESS OF VALUATION OF SIMILAR PROPERTIES
}

\begin{abstract}
The publication is dedicated to the possibility of using one of the basic descriptive parameters of statistical population, which is the coefficient of variation, to assess the set of similar properties in the estimation process. The publication sets the value of this ratio for the theoretical uniform and normal distribution depending on the difference: the maximum unit price - the minimum unit price. A part of the application development presents the results of analyses carried out at the stage of selection of similar real estates (using the coefficient of variation) in the implementation of two appraisal reports defining the value of
\end{abstract}


the property premises. These properties are located in towns Polanow and Mielno in Koszalin district, West Pomeranian Voivodeship. Data for the analysis were obtained from the Register of Real Estate Prices and Values.

Translated by Wojciech Cymerman, Joanna Cymerman

Keywords: property valuation, similar properties, coefficient of variation

JEL Code: R30 
